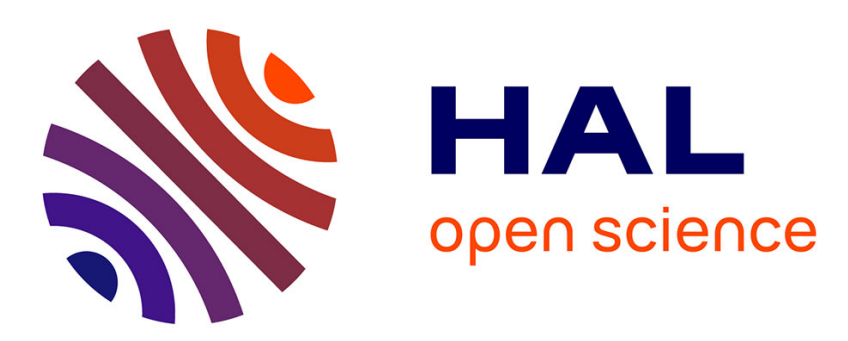

\title{
Effect of microstructure on continuous propagation of the Portevin-Le Chatelier deformation bands
}

D. Yuzbekova, A. Mogucheva, D. Zhemchuzhnikova, T. Lebedkina, M. Lebyodkin, R. Kaibyshev

\section{- To cite this version:}

D. Yuzbekova, A. Mogucheva, D. Zhemchuzhnikova, T. Lebedkina, M. Lebyodkin, et al.. Effect of microstructure on continuous propagation of the Portevin-Le Chatelier deformation bands. International Journal of Plasticity, 2017, 96, pp.210-226. 10.1016/j.ijplas.2017.05.004 hal-02357765

\section{HAL Id: hal-02357765 \\ https://hal.science/hal-02357765}

Submitted on 15 Nov 2021

HAL is a multi-disciplinary open access archive for the deposit and dissemination of scientific research documents, whether they are published or not. The documents may come from teaching and research institutions in France or abroad, or from public or private research centers.
L'archive ouverte pluridisciplinaire HAL, est destinée au dépôt et à la diffusion de documents scientifiques de niveau recherche, publiés ou non, émanant des établissements d'enseignement et de recherche français ou étrangers, des laboratoires publics ou privés. 


\title{
Effect of Microstructure on Continuous Propagation of the Portevin-Le Chatelier Deformation Bands
}

\author{
D. Yuzbekova ${ }^{\mathrm{a}}$, A. Mogucheva $\mathrm{a}^{\mathrm{a}}$, D. Zhemchuzhnikova ${ }^{\mathrm{a}, \mathrm{b}}$, T. Lebedkina ${ }^{\mathrm{b}}$, \\ M. Lebyodkin ${ }^{\mathrm{b}}$, R. Kaibyshev ${ }^{\mathrm{a}}$ \\ ${ }^{a}$ Belgorod State University, Pobedy 85, 308015 Belgorod, Russia \\ ${ }^{\mathrm{b}}$ Laboratoire d'Etude des Microstructures et de Mécanique des Matériaux (LEM3), \\ CNRS UMR 7239, Université de Lorraine, Ile du Saulcy, 57045 Metz, France \\ *Corresponding author: mogucheva@bsu.edu.ru
}

\begin{abstract}
Influence of severe plastic deformation (SPD) on plastic instability associated with the Portevin-Le Chatelier (PLC) effect was investigated in an AIMg alloy in a high strain-rate range corresponding to the well-known phenomenon of continuous propagation of PLC bands. Comparison with the model coarse-grained alloy reveals numerous unusual features of spatiotemporal behavior observed after different kinds of SPD processing that gives rise to an extreme grain refinement and an increase in the lattice dislocation density. Whereas SPD strongly alters the deformation curves, leading to either suppression of stress serrations or occurrence of serration types usually associated with static deformation bands, the band propagation persists in all material states. Surprisingly, smooth plastic deformation of the mostly work-hardened alloy neither corresponds to a uniform plastic flow but is related to propagation of a deformation band. The effect of the microstructure parameters on jerky flow can be explained through their influence on the propagation velocity and degree of localization of plastic deformation in the PLC bands. In particular, the loss of the PLC band mobility is discussed in relation with the conditions for the onset of necking and formation of the localized shear band leading to fracture.
\end{abstract}

Keywords: dislocations; microstructures; metallic material; mechanical testing; Portevin-Le Chatelier effect.

\section{Introduction}

Al-Mg alloys are susceptible to plastic instability giving rise to discontinuous yielding behavior associated with the Portevin-Le Chatelier (PLC) effect [1-7]. Its microscopic mechanism is generally ascribed to dynamic strain aging (DSA), i.e., dynamical pinning of dislocations by solutes during the waiting time of thermal activation of dislocations arrested on obstacles [2]. On the macroscopic scale, this phenomenon is manifested as jerky flow related to strain localization in the form of narrow bands of intense shear, which can be immobile or propagate along the sample [5-16]. The deformation bands leave undesirable traces on the surface of the sheet product during deep drawing, thus restricting the commercial application of Al-Mg alloys $[1,6,17]$. In addition, the PLC effect is harmful for formability because the PLC bands can lead to a premature onset of necking and fracture [17].

The relationships between jerky flow and nucleation and propagation of deformation bands were examined for several Al-based alloys, mostly with $\mathrm{Mg}$ as the main solute component [5- 
7,9-20]. Three major types of serrated tensile curves correspond to distinct band behaviors, as described, e.g., in $[3,5,20]$. Type $A$ serrations, recognized as flow stress raises followed by a drop to or below the general stress level, are associated with repetitive continuous propagation of deformation bands. The nucleation of a new band usually occurs at an angle of $\sim 60$ 을 to the tensile axis. The following stress drop correlates with the onset of propagation of the PLC band as a whole along the tensile axis. Type $B$ serrations typically occur about the general level of the stress-strain curve. They are attributed to a hopping, or relay-race, propagation of PLC bands. In this case, relatively regular stress oscillations are associated with consecutive nucleation, sometimes short-distance propagation, and disappearance of these bands. Type $C$ behavior is characterized by large stress drops below the general stress level. It is attributed to brief occurrence of immobile deformation bands nucleated virtually randomly along the tensile axis. Additional types $D$ and $E$ are sometimes distinguished for the propagation mode in order to take into account some specific shapes of deformation curves observed in alloys with complex composition [20]. The phenomenon of deformation band propagation attracts particular attention of researchers, notably because of its similarity with the propagation of the so-called Lüders band that results in a yield plateau and is often preceded by a stress drop (yield tooth) [21,22]. It was studied in detail in the case of steels [23$25]$ but is also well-known for Al-Mg alloys $[3,20]$.

Numerous efforts to improve usage properties of these alloys through precipitation hardening and/or extreme grain refinement showed that the specific microstructure can strongly influence on the jerky flow $[4,6,20,26-30]$. The latter approach to materials strengthening was suggested quite recently but quickly brought prominent results, although the increase in the strength was often accompanied with the ductility reduction (see review [31] and references therein). The observed effects of microstructure on serrated flow are divers and sometimes opposite to each other (the examples below correspond to roomtemperature tests). In particular, it was established that severe plastic deformation (SPD) resulting in an extensive grain refinement and a strong increase in the lattice dislocation density increases the critical strain for the onset of serrated flow and diminishes the serration amplitude and frequency, or even completely suppresses the PLC effect in dilute Al-Mg alloys or similar alloys containing coarse particles of secondary phases [27-30]. At the same time, the work hardening and, consequently, the ductility are considerably reduced. In contrast, the grain refinement was found to intensify the PLC instability without significant ductility reduction in Al-Mg alloys containing non-shearable nanoscale particles $[20,26]$. As far as the PLC band characteristics are concerned, there exists little literature. However, the available data provide clear evidence that both spatial and temporal behaviors of plastic instability depend on the microstructure $[5,9,32,33]$. Moreover, even investigations of PLC bands in coarse-grained binary alloys rendered contradictory results. For example, both an increase [9] and a decrease [32] in the band width were observed when the strain rate was increased. These examples prove the need of systematic and comprehensive investigations of the effect of initial microstructure on complex spatiotemporal behavior of the PLC instability.

The aim of the present work was to investigate complex spatiotemporal behavior of the PLC effect in the conditions of high-strain rate (type $A$ ) behavior in a "model" Al-Mg alloy with the initial microstructure modified using various SPD processes. Type $A$ behavior does not only attract interest as a striking example of collective dynamics of dislocations. Recently, it was found to dominate over other types in alloys containing additional microstructure elements, such as coherent precipitates or twin boundaries, which represent efficient obstacles to the dislocation motion (see, e.g. [16]). With this in mind, the investigated alloy was prepared with microstructures distinctly distinguished by the grain size and lattice dislocation density. The synchronous recording and comparison of the evolutions of the deforming stress and local 
strain-rate field allowed for exploring the relationships between strain localization and stress serrations, on the one hand, and the kinematics of nucleation and propagation of PLC bands, on the other hand.

\section{Material and experimental procedure}

Alloy with a chemical composition of Al-2.7Mg (wt. \%) was produced by semi-continuous casting. It also contained traces of $\mathrm{Fe}, \mathrm{Si}$ and $\mathrm{Zn}$ of $0.06,0.04$ and $0.03 \mathrm{wt}$. \%, respectively. The ingots were subjected to homogenization annealing for $4 \mathrm{~h}$ at $500^{\circ} \mathrm{C}$ and cooled with the furnace. Next, three different routes of thermomechanical processing were applied to produce three different microstructure conditions:

(i) Rectangular samples with dimensions of $40 \mathrm{~mm} \times 120 \mathrm{~mm} \times 200 \mathrm{~mm}$ were machined from the central part of the ingots and rolled at ambient temperature with a total reduction of $70 \%$ providing a final thickness of $\sim 4 \mathrm{~mm}$. The rolled sheets were annealed for $2 \mathrm{~h}$ at $400^{\circ} \mathrm{C}$ to produce recrystallized microstructure. This material condition is denoted hereafter as coarsegrained (CG);

(ii) Bars with dimensions of $20 \mathrm{~mm} \times 20 \mathrm{~mm} \times 100 \mathrm{~mm}$ were machined from the central part of the ingots and subjected to equal channel angular pressing (ECAP) via route $B_{c}$, in which the samples were rotated by $90^{\circ}$ along the same direction between each pass [34]. Two step pressing was used. The billets were initially pressed at $300^{\circ} \mathrm{C}$ up to a total strain of $\sim 8$ and then at $200^{\circ} \mathrm{C}$ up to a total true strain of $\sim 4$. This material condition is termed as fine-grained (FG).

(iii) Billets subjected to ECAP as described in item (ii) were additionally cold rolled with a total reduction of $80 \%$ down to a final thickness of $\sim 4 \mathrm{~mm}$ using a two-roller mill. This material condition is denoted as severely strained (SS).

Tensile specimens with a $35-\mathrm{mm}$ gauge length and $3 \times 7 \mathrm{~mm}^{2}$ cross-section were cut in the most often used geometry parallel to the last extrusion axis of the pressed billets and/or to the rolling direction of the sheets. Tensile tests were performed at room temperature and initial strain rates of $1 \times 10^{-3} \mathrm{~s}^{-1}$ and $5 \times 10^{-3} \mathrm{~s}^{-1}$ in a Zwick 1476 testing machine. Three samples were tested for each set of conditions. A strain gauge extensometer with $0.5 \%$ accuracy of strain measurement was applied to examine yielding behavior.

Digital image correlation (DIC) method was used to observe the PLC band kinematics because this technique provides a good combination of high spatial resolution, large field of vision, and relatively high acquisition rate (see, e.g., [35]). It consists in monitoring the evolution of a speckled sample surface during deformation, where the speckle is used as a mesh for calculation of the local strain and strain-rate fields. It was deposited by delicate spraying black paint on a white-painted specimen surface. The digital camera allowed for recording images of the speckle with a rate of $15 \mathrm{frames} / \mathrm{s}$ and spatial resolution about 25 pixels $/ \mathrm{mm}$. The calculations were performed using Vic-2D software (detail of this technique can be found, e.g., in [35]). The DIC system also provided a channel for recording the output signal of the testing machine. The accuracy of these measurements was relatively low, but they served to synchronize the series of images with the deformation curve recorded by the load cell. Such synchronization allowed for an accurate calculation of the velocity $V_{b}$ of the PLC bands which was measured as the rate of displacement of the position corresponding to the maximum local strain rate within the band, $\dot{\varepsilon}_{l o c}$.

Details of the structural characterization technique were reported in previous works [20]. Thin foils were examined using a JEM-2100 transmission electron microscope (TEM) with a double-tilt stage and an accelerating potential of $200 \mathrm{kV}$. The misorientations on the (sub)grain boundaries were studied using the orientation imaging microscopy (OIM) with automated indexing of electron back scattering diffraction (EBSD) patterns using a FEI Nova NanoSEM 
scanning electron microscope (SEM). The average grain size was evaluated from EBSD figures using the OIM software.

The investigation of the texture effect on the PLC instability goes beyond the scope of this paper and will be an object of the future work. This is partly justified by the fact that the Taylor factor $M$ determining the material strengthening due to accumulation of dislocations was found to be very close in all material conditions. Namely, the EBSD figures provided estimates $M=3.1$ (CG, FG) and $M=3.22$ (SS). It is also worth noting that very insignificant effects of texture on jerky flow were found up to now for Al-Mg [36] or Al-Cu [37] alloys that show relatively similar behaviors. Qualitative changes were only reported for the particular case of Al-Li alloys [38]. On the whole, although the texture evolution caused by SPD of Al-based alloys has been investigated in the literature, there exist very few data on the influence of texture on their jerky flow.

The dislocation density in the CG and FG material conditions was estimated by counting individual dislocations crossing the thin foil surface, according to [39]. In addition, the dislocation density in all three material conditions was evaluated by $\mathrm{X}$-ray diffraction (XRD) profile analysis using an ARL-Xtra diffractometer operated at $45 \mathrm{kV}$ and $35 \mathrm{~mA}$ with CuKa radiation. The value of the dislocation density $\rho$ was calculated using the Williamson-Hall method [40] from the average value of the crystallite size $D$, and microstrain $\varepsilon$, which are determined from XRD true peak broadening. The following relationship was used for calculations $[40,41]$ :

$\rho=\frac{3 \sqrt{2 \pi} \varepsilon^{1 / 2}}{D b}$,

where $b$ is the Burgers vector $\left(b=2.86 \times 10^{-10} \mathrm{~m}\right)$. The discrepancy between dislocation densities obtained by two methods in the CG and FG conditions was negligible. Averaged values are given below for the dislocation density.

\section{Results}

\subsection{Microstructure}

Typical microstructures of the studied $\mathrm{Al}-2.7 \% \mathrm{Mg}$ alloy in three different conditions are shown in Fig. 1 and quantified in Table 1. Black and white lines on the misorientation maps indicate high-angle boundaries (HABs) (>15ㅇ) and low-angle boundaries (LABs) ( $\leq 15 \%$ ), respectively. The microstructure of the CG alloy consists of coarse grains with approximately equiaxed shape (Fig. 1a). The lattice dislocation density is relatively low, as can be seen in the accompanying TEM micrograph in Fig. 1a'. Two structural components can be distinguished in the FG alloy (Fig. 1b). Average size of fine grains is $\sim 2 \mu \mathrm{m}$; their volume fraction is $\sim 90 \%$. Average size of coarse grains is $\sim 20 \mu \mathrm{m}$. However, their volume fraction is only $\sim 10 \%$. Both types of grains exhibit an elongated shape. TEM observations reveal that the LABs subdivide grains into crystallites having a round shape and average size of $\sim 460 \mathrm{~nm}$. The dislocation density is considerably increased is comparison with the CG state (Fig. 1 $b^{\prime}$ ). The subsequent extensive cold rolling affects insignificantly the grain size distribution and produces a very high lattice dislocation density in the SS conditions (Figs. 1c and $c^{\prime}$ ). On the whole, each microstructure condition is distinctly distinguished by the lattice dislocation density. Besides, average grain size in the CG material is twenty times higher than in the FG and SS material. The part of $\mathrm{HABs}$ and average misorientation are nearly the same in all material conditions. In all cases, grains are subdivided into subgrains by LABs. Most of LABs have misorientation less than $2^{\circ}$. As a result, the size of subgrains revealed by TEM is twice as low as that calculated from EBSD data. 


\subsection{Influence of microstructure on deformation behavior}

Typical engineering $\sigma-\varepsilon$ curves are presented in Fig. 2a for two strain rates and three material conditions. Figure $2 \mathrm{~b}$ shows enlarged small-strain parts of ?-? curves recorded at $\dot{\varepsilon}_{a}=5 \times 10^{-3} \mathrm{~s}^{-1}$ using the strain gauge extensometer. The values of the elastic limit (EL), $\sigma_{0.05}$, yield strength (YS), $\sigma_{0.2}$, ultimate tensile strength (UTS), $\sigma_{\mathrm{B}}$, and elongation-to-failure, $\delta$, are summarized in Table 2. The CG alloy exhibits mechanical behavior similar to other dilute Al$3 \% \mathrm{Mg}$ alloys with grain size $\geq 30 \mu \mathrm{m}$ in recrystallized condition $[7,28,42]$. Yielding occurs at a very low strain almost immediately after EL and is followed by a short yield plateau $[21,22]$. The values of $\mathrm{EL} \approx 70 \mathrm{MPa}$ and $\mathrm{YS} \approx 73 \mathrm{MPa}$ are quite close and correspond to a relative discrepancy $\left(\sigma_{0.2}-\sigma_{0.05}\right) / \sigma_{0.05} \approx 4 \%$. The following deformation is characterized by pronounced strain hardening up to the onset of necking, resulting in a very high $\sigma_{\mathrm{B}} / \sigma_{0.2}$ ratio (Table 2 ). Therewith, $\sigma_{B}$ is about $190 \mathrm{MPa}$, i.e., necking starts at a relatively low stress. The rate of strain hardening tends to decrease with increasing strain. Type $A$ serrations with the maximum amplitude of $\sim 4 \mathrm{MPa}$ can be distinguished on the deformation curves at both strain rates. The occurrence of plastic instability agrees with the fact that the deformation curves of CG specimens systematically lie below their counterparts measured at lower strain rates. Indeed, the negative strain-rate sensitivity (SRS) of the flow stress is a necessary condition of plastic instability ${ }^{1}$.

As can be seen in Fig. 2, grain refinement by ECAP leads to three-fold increases in the EL, up to $215 \mathrm{MPa}$, and YS, up to $235 \mathrm{MPa}$. In contrast to CG material, the elastoplastic transition displays a usual smooth shape resulting in a difference about $20 \mathrm{MPa}$ between EL and YS, i.e., almost 7 times higher than the above value for the CG material. The flow stress rises steadily with strain between the yield point and the necking stress but with a considerably lower work hardening rate than in the case of CG alloy. The elongation-to-failure decreases approximately by half. It is worth noting that this decrease in ductility is moderate in comparison with a fourfold decrease in the spread between UTS and YS. The UTS value varies from 250 to $270 \mathrm{MPa}$. In general, FG material also exhibits negative SRS, but this conclusion cannot be established unambiguously because of a strong variation of the deforming stress between samples processed by ECAP. This ambiguity is illustrated by a pair of deformation curves (FG) in Fig. 2a which both display plastic instability but show a higher deforming stress for the faster test. The range of stress serration amplitudes is even higher than in CG material and reaches $\sim 7 \mathrm{MPa}$. The FG alloy exhibits qualitatively different behavior of instability which represents a mixture of different types described in Sec. 1. Two specific morphologies of serrations were found for both strain rates. The example presented for $\dot{\varepsilon}_{a}=5 \times 10^{-3} \mathrm{~s}^{-1}$ displays a stair-case shape characteristic of type $D$ behavior. The other example represents a mixture of types $A$ and $B$ serrations.

Finally, additional cold rolling increases the yield stress up to $\sim 400 \mathrm{MPa}$. The SS alloy exhibits the highest discrepancy of $\sim 40 \mathrm{MPa}$ between EL and YS. The UTS and YS values become very close and the ductility drops down to several percents, so that extensive necking occurs soon after the onset of yielding. Negative SRS is clearly observed for all strains. However, it occurs that jerky flow is effectively suppressed by such treatment so that an apparent steady-state flow is observed, at least, before the onset of necking. The necking stage is in some cases accompanied with regular stress oscillations that have an appearance similar to type $C$ instability, in the sense that they occur below the envelope ?-? curve and can

\footnotetext{
${ }^{1}$ More exactly, this statement concerns the steady-state SRS determined by the solute concentration established after completion of the transitory processes following the change in the strain rate. This value should not be confused with the instantaneous SRS that is determined by the mechanism of thermal activation of dislocations and is always positive [2].
} 
be quite deep, with the maximum amplitude reaching 10 MPa. It is noteworthy that suppression of jerky flow by SPD was recently reported for a similar Al-3\%Mg alloy [28]. Such an effect was produced solely by ECAP, i.e., without additional cold-rolling. However, the ECAP treatment itself led to an increase in the yield strength up to $\sim 400 \mathrm{MPa}$, i.e., to a similar severely strained state.

In spite of the PLC instability associated with repetitive plastic flow localizations, it was verified that in all cases, the maximum load corresponds to the Considère strain for the onset of necking, which reflects the condition of the loss of stability of a homogeneous plastic flow [43]. An example of such verification is provided in Fig. 3. To evaluate the evolution of the work hardening exponent $n$ vs. true strain, stress serrations were smoothed out by fitting significant portions of deformation curves by $7^{\text {th }}$ order polynomials. The intersections of $n\left(\varepsilon_{\text {true }}\right)$-curves with the straight line $n=\varepsilon_{\text {true }}$ correspond to the Considère strain. The large circles indicate the position of the maximum load. It can be seen that the respective points practically coincide in the case of relatively smooth deformation curves observed in the SS alloy. Moreover, the correspondence is approximately satisfied in two other cases, in spite of the uncertainty caused by the fitting of strongly serrated curves. This behavior is different from that reported in Ref. [17] where jerky flow was observed to lead to premature necking with regard to the Considère condition. More specifically, in the present work, the absolute load maximum was occasionally observed slightly before the Considère strain when a serration was preceded by a strong rise in the load. However, the Considère condition was fulfilled for the averaged fitting curves.

\subsection{PLC band behavior}

The overall spatiotemporal behavior of the CG alloy agrees with the literature data on similar alloys. At the same time, the DIC technique allowed for getting new information on the strain geometry associated with deformation bands, as described below. As an example, strain-rate maps characterizing various deformation stages and the corresponding regions of the time-load curve of a specimen in CG condition are presented in Figs. 4-7. Figure 8a illustrates the evolution of the band velocity alongside with the true strain-true stress curve for the same specimen.

The yield plateau is related to nucleation and fast propagation of a deformation band from one specimen edge to the other (Fig. 4), in agreement with the generally accepted Lüders mechanism [21,22]. The first two frames seize the process of progressive nucleation of the band. This observation might explain the absence of a yield tooth that is known to often precede the Lüders plateau. The second frame clearly shows that the area of localized deformation has a concave shape. Its central part, corresponding to the highest $\dot{\varepsilon}_{l o c}$ values, displays a rounded contour. Although this aspect is less pronounced after complete formation of the deformation band, it can be recognized on all images. As a whole, the area of localized deformation is oriented horizontally, not as the usual representation of Lüders bands in the form of inclined plane-parallel bands corresponding to deformation by simple shear $[21,22]$. The maximum $\dot{\varepsilon}_{l o c}$ is only four times higher than the applied strain rate. That is, the localization of plastic flow is low in comparison with the PLC bands (cf. [9]). The last three frames capture the plastic flow homogenization after the band passage through the specimen. Indeed, they demonstrate delocalization of the high local strain rate zone, in the sense that the area of intense color spreads all over the sample while the maximum $\dot{\varepsilon}_{l o c}$ value decreases towards $\dot{\varepsilon}_{a}$.

Further strain hardening stage is characterized by continuous propagation of bands associated with type $A$ serrations (Figs. 5 and 6) $[6,9]$. In most cases, especially at low strains 
(Fig. 5), bands are nucleated near one specimen end and escape at the other end. Simultaneous occurrence of two deformation bands in different cross-sections was also observed. However, a transition from continuous to relay-race propagation, which if often reported for large strains (e.g., [20]), was not observed for the studied specimens. The bands observed at low strains have a usual plane shape corresponding to simple shear. They are inclined approximately at a $60^{\circ}$ angle from the tensile axis, as can be seen in Fig. 5 during the time interval from $21 \mathrm{~s}$ to $21.8 \mathrm{~s}$. However, they can turn symmetrically during propagation through the specimen. Importantly, this process does not occur as an abrupt flip but seems to involve a competition between two shear orientations, as particularly well seen at $t=21.9 \mathrm{~s}$. The band shape becomes similar to that observed on the yield plateau in Fig. 4. This aspect is intensified in the course of deformation, as illustrated in Fig. 6 . It can also be seen in Figs. 5 and 6 that work hardening leads to a gradual decrease in average band velocity (cf. Fig. 8a) and width, while the local strain rate within the band is increased, thus testifying to a stronger strain localization. At large strains (Fig. 6), the ratio $\dot{\varepsilon}_{l o c} / \dot{\varepsilon}_{a}$ exceeds 10 . For a plane-parallel band moving with a constant rate, the following relationships stem from geometrical consideration (cf., e.g., [13]): $\varepsilon_{b} V_{b}=\dot{\varepsilon}_{b} w=V$, where $\varepsilon_{b}$ and $\dot{\varepsilon}_{b}$ are the deformation band strain and strain rate, $w$ denotes its width, and $V$ is the mobile grip velocity. Although $w$ is not a well-defined characteristic because of the varying shape of deformation bands, these relationships are approximately verified for the data obtained. Deviations from these equalities can be caused by moving away from such an ideal case. Indeed, the estimates of the product $\dot{\varepsilon}_{l o c} w$ for the maximum $\dot{\varepsilon}_{l o c}$ values in Figs. 4-6 agree very well with the grip velocity in the case of the weak strain localization in the Lüders band but render almost twice as high values for the data of Fig. 6 . This increase testifies to strain localization strengthening within the deformation band.

Figure $8 a$ bears evidence that the evolution of the band velocity follows a unique approximately linear strain dependence all over the deformation curve. It can be suggested that in spite of the quantitative changes illustrated above, the dynamical mechanism governing the PLC band kinematics remains the same at different stages of work hardening. The final necking retains a sense of continuity with the above-described trends. It correlates with the termination of the propagation mode which is substituted with strain localization in a restricted area over which the deformation band performs slow movements forth and back (Fig. 7). Surprisingly, the data of Fig. 8a testify that $V_{b}$ does not vanish at the Considere strain but the propagation persists up to the position of the maximum true stress. More exactly, the band can still move over a distance of 3 to $10 \mathrm{~mm}$ after reaching the Considère strain. It should also be underlined that after the band immobilization, the $\dot{\varepsilon}_{l o c} / \dot{\varepsilon}_{a}$ ratio remains unchanged, i.e., about 10 , in contrast to the well-known immobile deformation bands responsible for type $C$ deformation curves, for which this factor is usually higher by two orders of magnitude [9]. The observed pattern of static bands alternates between two symmetrical orientations corresponding to a relatively plane contour of the deformation band. During the intermediate period, the strain localization area becomes virtually horizontal, with a concave outer contour and a rounded central part, as sketched in Fig. 9. The entire process thus includes reversal bending of the necking region. In contrast to the band propagation mode which on average produces uniform straining and the same reduction of the cross-section area all over the gage length of the specimen, the strain localization in a narrow region results in strong necking, visible with a naked eye, and fracture after several cycles depicted in Fig. 7.

In spite of the changes in stress serration patterns upon ECAP treatment (see Fig. 2), the main features of the PLC band kinematics in FG material deformed at high strain rate are similar to those in CG alloy, as illustrated in Figs. 10 and 11. First of all, quasi-continuous 
propagation of deformation bands is observed all over the deformation curve. More specifically, weak strain heterogeneity starts forming during elastoplastic transition as a diffuse area with $\dot{\varepsilon}_{l o c}$ slightly exceeding $\dot{\varepsilon}_{a}$ (not shown here). A well-defined PLC band appears at the yield point. Similar to the CG case, $\dot{\varepsilon}_{l o c}$ increases during the test; the $\dot{\varepsilon}_{l o c} w$ product is close to $V$ at small strains and considerably increases towards the UTS; $V_{b}$ decreases linearly with strain and does not completely vanish at the onset of necking (Fig. 8b); the further band immobilization during necking is associated with the strain localization geometry explained above in terms of the reversal bending. Quantitative comparison indicates that grain refinement reinforces localization of plastic deformation and reduces the mobility of PLC bands, in conformity with a certain tendency to type $B$ deformation curves. In particular, bands propagate over shorter distances in FG material. $V_{b}$ and $w$ are lower and $\dot{\varepsilon}_{l o c}$ is higher than in the CG state. As a matter of example, the maximum $V_{b}$-value is reduced by a factor of two. Finally, the stronger strain localization agrees with the observation that consecutive deformation bands propagate in reverse directions (see Fig. 10), which is also considered as a sign of type $B$ behavior, whereas type $A$ bands tend to propagate in the same direction [7]. On the other hand, the comparison of Figs. $8 \mathrm{a}$ and $8 \mathrm{~b}$ shows that the slopes of the $V_{b}\left(\varepsilon_{\text {true }}\right)$ dependences are very close for CG and FG alloys, in conformity with the insensitivity of these dependences to the work hardening during the tensile test.

The shape of deformation bands displayed in Fig. 10 deserves special attention. In comparison with the CG material, PLC bands observed after ECAP are relatively narrow from the beginning of plastic flow and clearly show plane geometry corresponding to shear deformation at an angle about $50^{\circ}$ to the tensile axis. Their width comprises 4 to $5 \mathrm{~mm}$, which is similar to the width of deformation bands in CG samples close to the UTS (Fig. 6) and does not visibly change during the test. This well-defined geometry helps one observe that the reversion of the propagation direction takes place through slowing down of the moving band and nucleation of a conjugate band oriented symmetrically, as shown in the frame at $t=9.49 \mathrm{~s}$ (cf. [6]). This virtually immobile configuration is unstable. The next frame illustrates that one of the bands is strengthened at the expense of its counterpart and the propagation resumes. The period of the competition between two bands or, more generally, slowing down and resuming the band propagation, corresponds to visible stress fluctuations on the deformation curve. Importantly, the clear observation of the intersection of two conjugate bands confirms the scheme suggested in Fig. 9 to explain the concave shape of strain localization areas in Figs. 4-7 (see also Fig. 11) in terms of a competition between two deformation bands with "shear" orientation.

Figures 12 and 13 illustrate spatiotemporal behavior of plastic flow of SS material at the same applied strain rate. It can be seen that the main features underlined above, i.e., the deformation band propagation mode before necking (Fig. 12) and static strain localization during necking (Fig. 13), remain valid in this case, too. The quantitative trends also persist. Namely, $V_{b}$ is further reduced in comparison with the FG alloy, in line with the $V_{b}$ reduction upon ECAP as compared with the CG material. Some decrease in $V_{b}$ (see Fig. 8c) and increase in $\dot{\varepsilon}_{l o c}$ with straining can be detected, although the drastically decreased ductility does not allow for establishing the $V_{b}\left(\varepsilon_{\text {true }}\right)$-dependence (a straight line is provided as a guide for the eye).

Finally, visualization of the deformation band kinematics sheds light on the occurrence of stress oscillations during necking at $\dot{\varepsilon}_{a}=10^{-3} \mathrm{~s}^{-1}$. The pattern shown in Fig. 14 is qualitatively similar to those of Figs. 7, 11, and 13. One of its essential features is a persistent concave shape testifying to a competition between two conjugate shear bands (see Fig. 9). Similar to the previous cases, the necking region undergoes reversal bending reflected in the alternation of the dominant band orientation. However, in contrast to the above-described patterns, the 
degree of strain localization strongly fluctuates in Fig. 14. Approaching the stress peak proceeds along with the deformation band shrinkage and a five-fold increase in $\dot{\varepsilon}_{l o c}$. This highrate plastic deformation results in fast drops in stress and $\dot{\varepsilon}_{l o c}$, as well as deformation band widening. The $\dot{\varepsilon}_{l o c}$ value alternates between $3 \times 10^{-1} \mathrm{~s}^{-1}$ and $5 \times 10^{-2} \mathrm{~s}^{-1}$. This interval corresponds to a variation of the $\dot{\varepsilon}_{l o c} / \dot{\varepsilon}_{a}$ ratio from 30 to 5 . Thus, the stress oscillations are associated with the alternating localization and delocalization of plastic deformation. It is noteworthy that in spite of the visual resemblance between these stress oscillations and type $C$ serrations, the spatiotemporal pattern uncovers significant differences. Indeed, type $C$ deformation bands correspond to very short and intense strain localizations alternating with long periods of virtually uniform plastic deformation of the entire specimen. In contrast, the deformation band shown in Fig. 14 is present in each image and corresponds to a relatively low $\dot{\varepsilon}_{l o c} / \dot{\varepsilon}_{a}$ ratio (cf. [9]).

\section{Discussion}

Mechanical tests show that SPD leads to radical modifications in the plasticity and fracture properties of the dilute Al-Mg alloy investigated in the present paper. Whereas the CG alloy displays a yield plateau followed by type $A$ stress serrations in the studied range of high strain rates, the yield plateau disappears and the morphology of the deformation curves is altered by the SPD. More exactly, a mixture of types $A, B$ and $D$ serrations is observed after ECAP; smooth curves are found after subsequent cold rolling. These results could make think of possible changes in the dynamical mechanism of the PLC effect upon severe plastic deformation. Surprisingly, visualization of spatiotemporal behavior of deformation bands testifies to the same underlying dynamical mechanism associated with the deformation band propagation. Besides the similarity of the local strain-rate maps, this conjecture is corroborated by the observation of a unique dependence describing the evolution of the band velocity during deformation of materials in different initial conditions. It can be suggested that the qualitative differences in jerky flow are caused by the effect of the material strengthening on the mobility of the PLC deformation bands, be it due to a preliminary SPD processing or work hardening during the test.

To illustrate possible scenarios, let us consider a specific example presented in Fig. 12 which helps one understand how the similar band kinematics can be associated with different morphologies of deformation curves, smooth in this case (SS alloy) and serrated in either CG or FG conditions. It can be seen that the entire test corresponds to the propagation and ultimate immobilization of a single deformation band. The first five frames demonstrate its gradual development during the elastoplastic transition. The band occurs in the form of a round area near one specimen side and expands to the opposite side. At the same time, the maximum local strain rate within the band increases by a factor of five. The yield point is associated with the completion of the transformation of the localized strain area to a plane deformation band. The whole pattern is analogous to the nucleation and motion of a Lüders band (cf. Fig. 4). Since $V_{b}$ and $\dot{\varepsilon}_{l o c}$ do not change abruptly but evolve continuously during the band motion, the deformation curve is smooth and only demonstrates slight fluctuations. In contrast, the nucleation of subsequent bands or discontinuities in their propagation gives rise to macroscopic stress serrations in the cases of CG and FG alloys.

The data obtained also shed light on the relationship between the PLC instability and necking, i.e., the general phenomenon associated with formation of a localized shear band leading to fracture of a ductile material. On the one hand, according to Figs. 3 and 8 , the 
necking condition and the evolution of the PLC band velocity are both controlled by the evolution of the work hardening but are not directly related to each other. On the other hand, the entirety of strain-rate maps show that fracture takes place in the section where the last PLC band has been immobilized. It follows that in the presence of strain localization caused by the PLC instability, the intense plastic flow within the slowing down PLC band influences on the necking development and helps stabilize and form the ultimate localized shear band (cf. [17]). This conjecture can again be illustrated by the previous example. Indeed, an essential difference between the SS alloy and other conditions is that the deformation band moves over a short distance about one fourth of the specimen gage length. Therefore, whereas average deformation of CG and FG samples is roughly uniform because the deformation bands propagate through the entire specimen, the SS samples exhibit no true uniform elongation. As the deformation band provides the major contribution to plastic strain, an essential part of the specimen remains virtually undeformed, except for an insignificant strain accumulated due to more uniform deformation during the elastoplastic transition. The low ductility of SS samples can thus be associated with the restricted mobility of the PLC band, which results in an extreme strain heterogeneity and premature termination of the band propagation. This logic also applies to explain the lower ductility of FG samples as compared with CG material.

The results obtained can be rationalized in the following framework. Two competing processes occur during mechanical tests. First, strain hardening stems from the increasing dislocation density. It proceeds in a localized manner in the case of plastic instability because strain localization within PLC bands locally hardens the material by increasing the local dislocation density. However, the PLC band propagation from one specimen end to the other one raises the dislocation density in the entire volume of the sample and provides uniform deformation on average. Second, as testified by the observation of the negative strain rate sensitivity in all three microstructural conditions, the alloy undergoes strain-rate softening, in agreement with the DSA mechanism of the PLC effect. It is the strain-rate softening that causes the formation of PLC bands characterized by a local strain rate significantly exceeding the applied value. In other words, strain hardening is a stabilizing factor while strain-rate softening gives rise to plastic instability. It follows that the band propagation velocity and the degree of the local strain-rate increment are concurrent factors, in the sense that the decreasing mobility of the PLC band is accompanied by the increasing local strain rate within it [44]. Finally, it needs be specified that the onset of plasticity involves strain softening phenomenon due to breakthrough of statically aged dislocations from solute clouds. This phenomenon is usually applied to explain the propagation of a Lüders band during the yield plateau $[21,22]$.

The effect of the initial microstructure state on the PLC band behavior can then be attributed to changing the conditions of the competition between the strain hardening and strain-rate softening. It is known that the failure of Al-3\%Mg alloys occurs when the dislocation density approaches locally the critical value $\rho \sim 10^{15} \mathrm{~m}^{-2}$ corresponding to the dislocation spacing about $10 \mathrm{~nm}[42,45]$. In the CG state, the initial dislocation density is two orders of magnitude lower than the critical value. Estimates of the dislocation strengthening ${ }^{2}$ using $\rho$ values from Table 1 provide a value $\sigma_{d} \sim 17 \mathrm{MPa}$ that only comprises about $23 \%$ of $\sigma_{0.2}$ (see Table 2). On the one hand, the low initial dislocation density makes possible the occurrence of a yield plateau through propagation of a deformation band into the initially "soft" material. On the other hand, the low dislocation density makes the material prone to strain hardening. Besides, the $\dot{\varepsilon}_{l o c} / \dot{\varepsilon}_{a}$ ratio is relatively small at the beginning of deformation. Respectively, $V_{b}$ is quite high (Table 3 ), although it decreases in the course of deformation along with the strain

\footnotetext{
${ }^{2}$ The dislocation strengthening was estimated as $\sigma_{d}=M \alpha G b \rho^{0.5}$ where $\alpha$ is a constant $(0.24$ for $f c c$ metals) and $G$ is the shear modulus of aluminum $(25.4 \mathrm{GPa})$.
} 
hardening rate (see also below). The initial dislocation density is increased 15 times upon ECAP (Table 1). One consequence is that it prevents from formation of a Lüders band upon reaching the elastic limit. Accordingly, the yield stress is observed to exceed the elastic limit significantly, which can be explained by the need of high internal stresses in order to warrant the nucleation and propagation of a deformation band. At the same time, the grain refinement provides an important contribution to the material strengthening $\left(\sigma_{d} / \sigma_{0.2} \sim 28 \%\right.$ remains relatively low) so that the FG alloy displays a lower capacity to work harden (Fig. 2) and the $\dot{\varepsilon}_{l o c} / \dot{\varepsilon}_{a}$ ratio attains a factor of 10 in the very first PLC band (Fig. 10). Therefore, the balance between two factors is shifted, which might explain the two-fold decrease in the deformation band velocity. In the SS alloy, the initial dislocation density approaches the critical range $\left(\sigma_{d} / \sigma_{0.2} \sim 73 \%\right)$. Consequently, this material is not susceptible to strain hardening and PLC behavior is controlled by the local strain-rate softening. A single nearly stationary PLC band slowly evolves after yielding and the localization of plastic deformation leads to an early fracture (cf. [35]).

The shapes of the deformation curves of CG and FG samples reflect the fact that the ability of the Al-Mg alloy to strain hardening diminishes when the strain increases and the dislocation density grows towards the critical value. Consequently, $v_{b}$ decreases during the test and the PLC bands lose their mobility and considerably slow down close to the Considère strain. An immobilized PLC band eventually serves to form the ultimate localized shear band. Therewith, the reversal bending due to the repetitive occurrence of a conjugated band prevents from resuming the band propagation and, therefore, promotes premature fracture. To summarize, the proposed scheme allows for discussing the role of the strain localization caused by the PLC instability in the ultimate necking and explaining the effect of SPD on the ductility of the Al-Mg alloy. It should be however noted that this scheme only considers the work hardening controlled by the evolution of the dislocation density and disregards other contributions to the material strengthening (see, e.g., [30]). Therefore, it does not provide an interpretation of the large difference between the necking/fracture stresses for three material conditions.

\section{Conclusions}

1. The Al-2.7\%Mg alloy with grain sizes and lattice dislocation density of, respectively, 40 $\mu \mathrm{m}$ and $10^{13} \mathrm{~m}^{-2}$ (CG material) exhibits type $A$ stress serrations at $\dot{\varepsilon} \geq 1 \times 10^{-3} \mathrm{~s}^{-1}$ and ambient temperature. The FG alloy $\left(2 \mu \mathrm{m} ; 1.5 \times 10^{14} \mathrm{~m}^{-2}\right)$ displays more complex behavior comprising a mixture of type $A, B$, and $D$ serrations. The SS alloy $\left(2 \mu \mathrm{m} ; 2.7 \times 10^{15} \mathrm{~m}^{-2}\right)$ exhibits smooth plastic flow. Surprisingly, all these types of behavior are associated with the same dynamical mechanism consisting in the propagation of deformation bands. The PLC band velocity shows qualitatively similar dependence on the true strain during deformation of differently processed materials. Moreover, due to large elongation before fracture of CG and FG alloys, it was established that this dependence is described by a similar linear decreasing function for both material conditions. The qualitative differences between patterns of stress serrations can be rationalized in terms of the effect of microstructure parameters on the deformation band mobility.

2. The CG alloy exhibits a short yielding plateau associated with the nucleation and fast propagation of a deformation band. In contrast to the usual representation of Lüders bands corresponding to shear deformation in an inclined plane [21,22], this band is oriented normally to the tensile axis, which may be due to coexistence of two wide conjugate bands. In the FG and SS materials, the first deformation band starts developing after reaching the elastic limit. The yield point is attributed to the formation of a well-defined PLC band. 
3. The highest velocity of the PLC band propagation and the lowest local strain rate within the band are observed in the CG alloy exhibiting the highest ductility. The grain refinement and the increasing dislocation density strongly increase the deforming stress level and decrease the work hardening capacity of the material. These changes in the microstructure state result in lower band velocities and higher local strain-rate values within the deformation band.

4. In spite of the presence of the PLC instability associated with repetitive plastic flow localizations, the onset of necking corresponds well to the Considère strain that reflects the condition of the loss of stability of a homogeneous plastic flow. At the same time, the development of the neck is closely related to the loss of mobility of the PLC band. More exactly, the intense plastic flow within the slowing down PLC band serves to form the ultimate localized shear band. In particular, the low ductility of the SS alloy is observed together with a low mobility of the PLC band which does not propagate through the entire specimen length. The displacement of the band along the tensile axis, which characterizes the strain hardening stage, is substituted by a process consisting in a repeated growth and collapse of two deformation bands developing in two non-coplanar directions and alternating with each other. Such alternation produces reversal bending in the necked region. Stress oscillations resembling type $C$ behavior are sometimes observed during necking of SS samples. Such oscillations are caused by periodic variations in the degree of localization of plastic deformation within the pair of conjugate deformation bands.

\section{Acknowledgments}

The authors thank M. Jrad for providing the DIC setup and valuable consultations. The financial support received from the Ministry of Education and Science, Russia, (Belgorod State University project №14.587.21.0018 (RFMEFI58715X0018)) is acknowledged. The microstructure analysis and a part of mechanical tests were performed using equipment of Joint Research Center, Belgorod State University. Mechanical tests combined with DIC experiments were realized in LEM3. T. L. acknowledges support by the Region Lorraine (France) and the Center of Excellence "LabEx DAMAS" (Grant ANR-11-LABX-0008-01 of the French National Research Agency).

\section{References}

[1] A. Portevin, F. Le Chatelier, Sur un phenomene observe lors de l'essai de traction d'alliages en cours de transformation, Compt. Rend. Acad. Sci. Paris 176 (1923) 507-510.

[2] P.G. McCormick, Theory of flow localization due to dynamic strain ageing, Acta metall. 36 (1988) 3061-3067.

[3] I.V. Shashkov, M.A. Lebyodkin, T.A. Lebedkina, Multiscale study of acoustic emission during smooth and jerky flow in an AlMg alloy, Acta Mater. 60 (2012) 6842-6850. DOI: 10.1016/j.actamat.2012.08.058

[4] H. Aboulfadl, J. Deges, P. Choi, D. Raabe, Dynamic strain aging studied at the atomic scale, Acta Mater. 86 (2015) 34-42. DOI: 10.1016/j.actamat.2014.12.028

[5] H. Jiang, Q. Zhang, X. Chen, Z. Chen, Z. Jiang, X. Wu, J. Fan, Three types of Portevin-Le Chatelier effects: Experiment and modelling, Acta Mater. 55 (2007) 2219-2228. DOI: 10.1016/j.actamat.2006.10.029

[6] H. Halim, D.S. Wilkinson, M. Niewczas, The Portevin-Le Chatelier (PLC) effect and shear band formation in an AA5754 alloy, Acta Mater. 55 (2007) 4151-4160. DOI: 10.1016/j.actamat.2007.03.007 
[7] H. Ait-Amokhtar, C. Fressengeas, Crossover from continuous to discontinuous propagation in the Portevin-Le Chatelier effect, Acta Mater. 58 (2010) 1342-1349. DOI: 10.1016/j.actamat.2009.10.038

[8] P.D. Zavattieri, V. Savic, L.G. Hector Jr., J.R. Fekete, W. Tong, Y. Xuan, Spatio-temporal characteristics of the Portevin-Le Châtelier effect in austenitic steel with twinning induced plasticity, Int. J. Plast. 25 (2009) 2298-2330. DOI: 10.1016/j.ijplas.2009.02.008

[9] H. Ait-Amokhtar, P. Vacher, S. Boudrahem, Kinematics fields and spatial activity of Portevin-Le Chatelier bands using the digital image correlation method, Acta Mater. 54 (2006) 4365-4371. DOI: 10.1016/j.actamat.2006.05.028

[10] R. Nogueiro de Codes, O.S. Hopperstad, O. Engler, O.-G. Lademo, J.D. Embury, A. Benallal, Spatial and temporal characteristics of propagating deformation bands in AA5182 alloy at room temperature, Metall. Mater. Trans. A 42 (2012) 3358-3369. DOI: 10.1007/s11661-011-0749-1

[11] L. Casarotto, H. Dierke, R. Tutsch, H. Neuhauser, On nucleation and propagation of PLC bands in an Al-3Mg alloy, Mater. Sci. Eng. A 527 (2009) 132-140. DOI: 10.1016/j.msea.2009.07.043

[12] H. Louche, K. Bouabdallah, P. Vacher, T. Coudert, P. Balland, Kinematic fields and acoustic emission observations associated with the Portevin Le Chatelier effect on an Al-Mg alloy, Exp. Mech. 48 (2008) 741-751. DOI: 10.1007/s11340-008-9125-5

[13] X. Feng, G. Fischer, R. Zielke, B. Svendsen, W. Tillmann, Investigation of PLC band nucleation in AA5754, Mater. Sci. Eng. A 539 (2012) 205-210. DOI: 10.1016/j.msea.2012.01.082

[14] P.Y. Manach, S. Thuillier, J.W. Yoon, J. Coer, H. Laurent, Kinematics of Portevin-Le Chatelier bands in simple shear, Int. J. Plast. 58 (2014) 66-83. DOI: 10.1016/j.ijplas.2014.02.005

[15] A. Benallal, T. Berstad, T. Børvik, O.S. Hopperstad, I. Koutiri, R. Nogueira de Codes, An experimental and numerical investigation of the behaviour of AA5083 aluminium alloy in presence of the Portevin-Le Chatelier effect, Int. J. Plast. 24 (2008) 1916-1945. DOI: 10.1016/j.ijplas.2008.03.008

[16] D.A. Zhemchuzhnikova, M.A. Lebyodkin, T.A. Lebedkina, R.O. Kaibyshev, Unusual behavior of the Portevin-Le Chatelier effect in an AlMg alloy containing precipitates, Mater. Sci. Eng. A 639 (2015) 37-41. DOI: 10.1016/j.msea.2015.04.094

[17] J. Kang, D.S. Wilkinson, M. Jain, J.D. Embury, A.J. Beaudoin, S. Kim, R. Mishira, A.K. Sachdev, On the sequence of inhomogeneous deformation processes occurring during tensile deformation of strip cast AA5754, Acta Mater. 54 (2006) 209-218. DOI: 10.1016/j.actamat.2005.08.045

[18] B. Klusemann, G. Fischer, Th. Böhlke, B. Svendsen, Thermomechanical characterization of Portevin-Le Chatelier bands in AlMg3 (AA5754) and modeling based on a modified EstrinMcCormick approach, Int. J. Plast. 67 (2015) 192-216. DOI: 10.1016/j.jplas.2014.10.011

[19] A.A. Shibkov, M.F. Gasanov, M.A. Zheltov, A.E. Zolotov, V.I. Ivolgin, Intermittent plasticity associated with the spatio-temporal dynamics of deformation bands during creep tests in an AlMg polycrystal, Int. J. Plast. 86 (2016) 37-55. DOI: 10.1016/j.ijplas.2016.07.014

[20] A. Mogucheva, D. Yuzbekova, R. Kaibyshev, T. Lebedkina, M. Lebyodkin, Effect of Grain Refinement on Jerky Flow in an Al-Mg-Sc Alloy, Metall. Mater. Trans. A 47 (2016) 2093-2106. DOI: $10.1007 / \mathrm{s} 11661-016-3381-2$

[21] R. Schwab, V. Ruff, On the nature of the yield point phenomenon, Acta Mater. 61 (2013) 1798-1808. DOI: 10.1016/j.actamat.2012.12.003

[22] S.D. Antolovich, R.W. Armstrong, Plastic strain localization in metals: origins and consequences, Prog. Mater. Sci. 59 (2014) 1-160. DOI: 10.1016/j.pmatsci.2013.06.001 
[23] M.R. Wenman, P.R. Chard-Tuckey, Modelling and experimental characterisation of the Lüders strain in complex loaded ferritic steel compact tension specimens, Int. J. Plast. 26 (2010) 1013-1028. DOI: 10.1016/j.ijplas.2009.12.005

[24] J.F. Hallai, S. Kyriakides, Underlying material response for Lüders-like instabilities, Int. J. Plast. 47 (2013) 1-12. DOI: 10.1016/j.ijplas.2012.12.002

[25] M. Mazière, C. Luis, A. Marais, S. Forest, M. Gaspérini, Int. J. Solids Struct. 06-107 (2017) 305-314. DOI: 10.1016/j.ijsolstr.2016.07.026

[26] S. Zhao, C. Meng, F. Mao, W. Hu, G. Gottstein, Influence of severe plastic deformation on dynamic strain aging of ultrafine grained Al-Mg alloys, Acta Mater. 76 (2014) 54-67. DOI: 10.1016/j.actamat.2014.05.004

[27] A. Sarkar, P. Barat, P. Mukherjee, Investigation of Portevin-Le Chatelier effect in Al-2.5 pct Mg alloy with different microstructure, Metall. Mater. Trans. A 44 (2013) 2604-2612. DOI: 10.1007/s11661-013-1630-1

[28] T.A. Lebedkina, M.A. Lebyodkin, T.T. Lamark, M. Janeček, Y. Estrin, Effect of equal channel angular pressing on the Portevin-Le Chatelier effect in an Al3Mg alloy, Mater. Sci. Eng. A 615 (2014) 7-13. DOI: 10.1016/j.msea.2014.07.064

[29] M. Wagenhofer, M. Erickson-Natishan, R.W. Armstrong, F.J. Zerilli, Influences of strain rate and grain size on yield and serrated flow in commercial Al-Mg alloy, Scr. Mater. 41 (1999) 1177-1184. DOI: 10.1016/S1359-6462(99)00265-1

[30] P. Bazarnik, M. Lewandowska, K.J. Kurzydlowski, Arch. Metall. Mater. 57 (2012) 869876. DOI: $10.2478 / v 10172-012-0096-2$

[31] M.A. Meyers, A. Mishra, D.J. Benson, Mechanical properties of nanocrystalline materials, Progr. Mater. Sci. 51 (2006) 427-556. DOI:10.1016/j.pmatsci.2005.08.003

[32] K. Chihab, Y. Estrin, L.P. Kubin, J. Vergnol, The kinetics of the Portevin-Le Chatelier effect in an Al-5at\%Mg alloy, Scripta Metall. 21 (1987) 203-208. DOI: 10.1016/00369748(87)90435-2

[33] C. Bernard, J. Coër, H. Laurent, P.Y. Manach, M. Oliveira, L.F. Menezes, Exp. Mech. 57 (2017) 405-415. DOI:10.1007/s11340-016-0229-z

[34] R.Z. Valiev, T.G. Langdon, Principles of equal-channel angular pressing as a processing tool for grain refinement, Prog. Mater. Sci. 51 (2006) 881-981. DOI: 10.1016/j.pmatsci.2006.02.003

[35] Y.L. Cai, S.L. Yang, Y.H. Wang, S.H. Fu, Q.C. Zhang, Characterization of the deformation behaviors associated with the serrated flow of a 5456 Al-based alloy using two orthogonal digital image correlation systems, Mater. Sci. Eng. A 664 (2016) 155-164. DOI: 10.1016/j.msea.2016.04.003.

[36] M. Eddahbi, M.A. Monge, A. Muñoz, R. Pareja, Serrated flow in powder metallurgy Al$5 \% \mathrm{Mg}-1.2 \% \mathrm{Cr}$ alloy processed by equal channel angular pressing, Mater. Charact. 73 (2012) 16-30

[37] T. Böhlke, G. Bondár, Y. Estrin, M.A. Lebyodkin, Geometrically non-linear modeling of the Portevin-Le Chatelier effect, Comput. Mater. Sci. 44 (2009) 1076-1088

[38] Y.Z. Shen, K.H. Oh, D.N. Lee, The effect of texture on the Portevin-Le Chatelier effect in 2090 Al-Li alloy, Scripta Mater. 51 (2004) 285-289

[39] P.B. Hirsh, A. Howie, R.B. Nicholson, D.W. Pashley, M.J. Whelan, Electron Microscopy of Thin Crystals, Butterworths, London, 1965.

[40] G.K. Williamson, W.H. Hall, X-ray line broadening from filed aluminum and wolfram, Acta Metall. 1 (1953) 22-31. DOI: 10.1016/0001-6160(53)90006-6. 
[41] G. Dini, R. Ueji, A. Najafizadeh, S.M. Monir-Vaghefi, Flow stress analysis of TWIP steel via the XRD measurement of dislocation density, Mater. Sci. Eng. A 527 (2010) 2759-2763. DOI: 10.1016/j.msea.2010.01.033.

[42] M. Jobba, R.K. Mishra, M. Niewczas, Flow stress and work-hardening behaviour of AlMg binary alloys, Int. J. Plast. 65 (2015) 43-60. DOI: 10.1016/j.ijplas.2014.08.006.

[43] A.G. Considère, Mémoire sur l'emploi du fer et de l'acier dans les constructions. Annales des Ponts et Chausses (ser. 6) 9 (1885) 574-775.

[44] Y. Brechet, G. Canova, L.P. Kubin, Strain softening, slip localization and propagation: from simulations to continuum modelling, Acta Mater. 44 (1996) 4261-4271. DOI: 10.1016/1359-6454(96)00115-2.

[45] D.Y. Park, M. Niewczas, Plastic deformation of Al and AA5754 between $4.2 \mathrm{~K}$ and $295 \mathrm{~K}$, Mater. Sci. Eng. A 491 (2008) 88-102. DOI: 10.1016/j.msea.2008.01.065.

Table 1. Microstructural characteristics (the fraction of high-angle boundaries, HABs, the average misorientation, $\Theta_{\mathrm{av}}$, the grain size, $d$, and the lattice dislocation density, $\rho$ ) of the Al2.7\%Mg alloy in different conditions.

\begin{tabular}{|c|c|c|c|c|}
\hline State & HABs, $\%$ & $\Theta_{\mathrm{av},}{ }^{\circ}$ & $\mathrm{d}, \mu \mathrm{m}$ & $\rho, \mathrm{m}^{-2}$ \\
\hline CG & 47 & 20.9 & 40 & $1.0 \times 10^{13}$ \\
\hline FG & 37 & 18.7 & 2 & $1.5 \times 10^{14}$ \\
\hline SS & 40 & 18.9 & 2 & $2.7 \times 10^{15}$ \\
\hline
\end{tabular}

Table 2. Mechanical properties (the elastic limit, $\sigma_{0.05}$, the yield strength, $\sigma_{0.2}$, the ultimate tensile strength, $\sigma_{\mathrm{B}}$, and the elongation-to-failure, $\delta$ ) of the $\mathrm{Al}-2.7 \% \mathrm{Mg}$ alloy tested at a strain rate of $5 \times 10^{-3} \mathrm{~s}^{-1}$ in different microstructure conditions.

\begin{tabular}{|c|c|c|c|c|c|c|}
\hline State & $\sigma_{0.05}, \mathrm{MPa}$ & $\sigma_{0.2}, \mathrm{MPa}$ & $\sigma_{0.2} / \sigma_{0.05}$ & $\sigma_{\mathrm{B}}, \mathrm{MPa}$ & $\sigma_{\mathrm{B}} / \sigma_{0.2}$ & $\delta, \%$ \\
\hline $\mathrm{CG}$ & 70 & 73 & 1.04 & 195 & 2.67 & 38.0 \\
\hline FG & 215 & 235 & 1.09 & 270 & 1.15 & 18.0 \\
\hline SS & 360 & 400 & 1.11 & 410 & 1.03 & 10.5 \\
\hline
\end{tabular}


Figure 1. EBSD misorientation maps (a-c) and TEM micrographs ( $\left.a^{\prime}-c^{\prime}\right)$ of the Al-2.7\%Mg alloy in coarse-grained $\left(a, a^{\prime}\right)$, fine-grained $\left(b, b^{\prime}\right)$ and severely strained $\left(c, c^{\prime}\right)$ conditions.
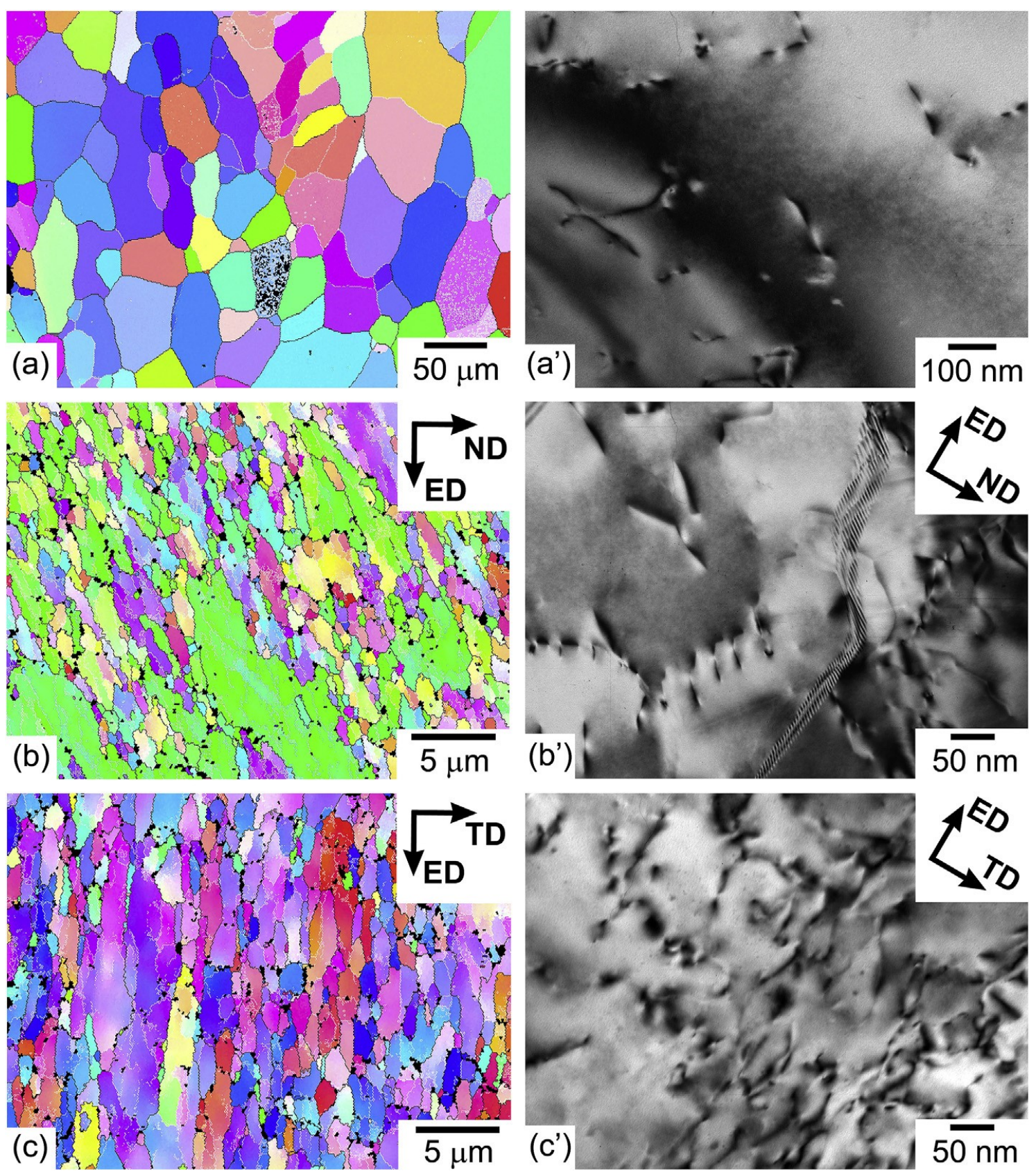
Figure 2. (a) Examples of deformation curves of the Al-2.7\%Mg alloy for three different microstructure conditions and two strain rate values indicated by arrows; (b) initial portions of deformation curves for the strain rate of $5 \times 10^{-3} \mathrm{~s}^{-1}$, obtained with the aid of a high-resolution extensometer.
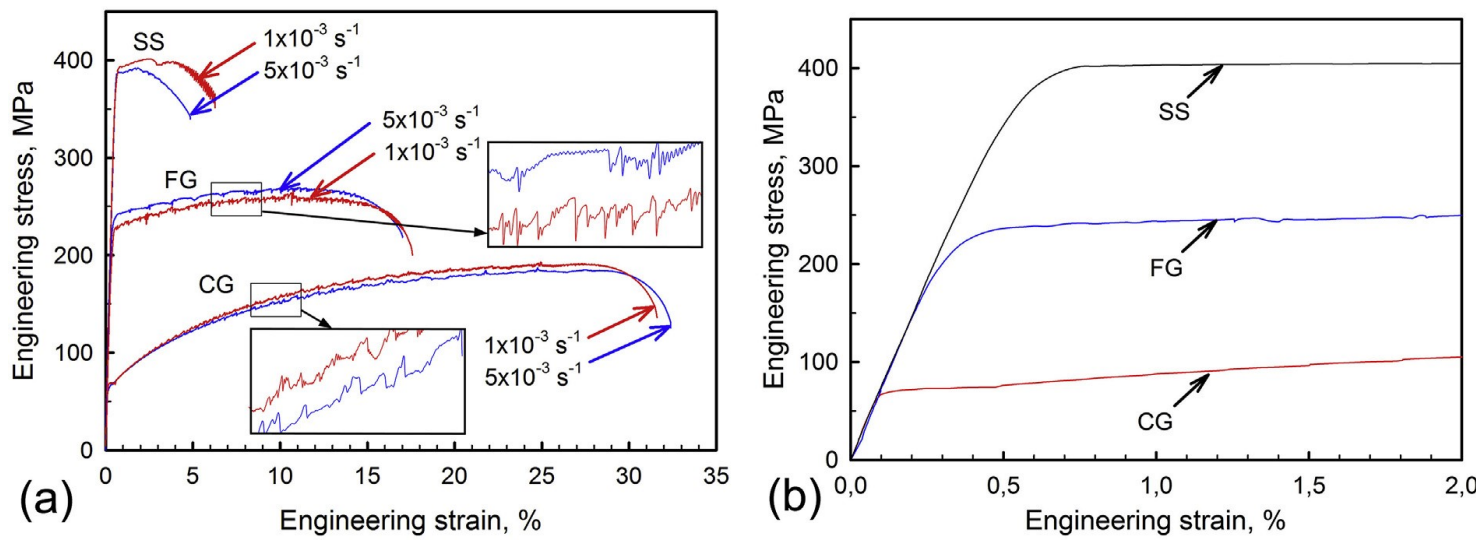

Figure 3. Examples of evolution of the work hardening exponent $n$ vs. true strain $\varepsilon_{\text {true. }}$ Large circles indicate the position of the maximum load. $\dot{\varepsilon}_{a}=5 \times 10^{-3} \mathrm{~s}^{-1}$.

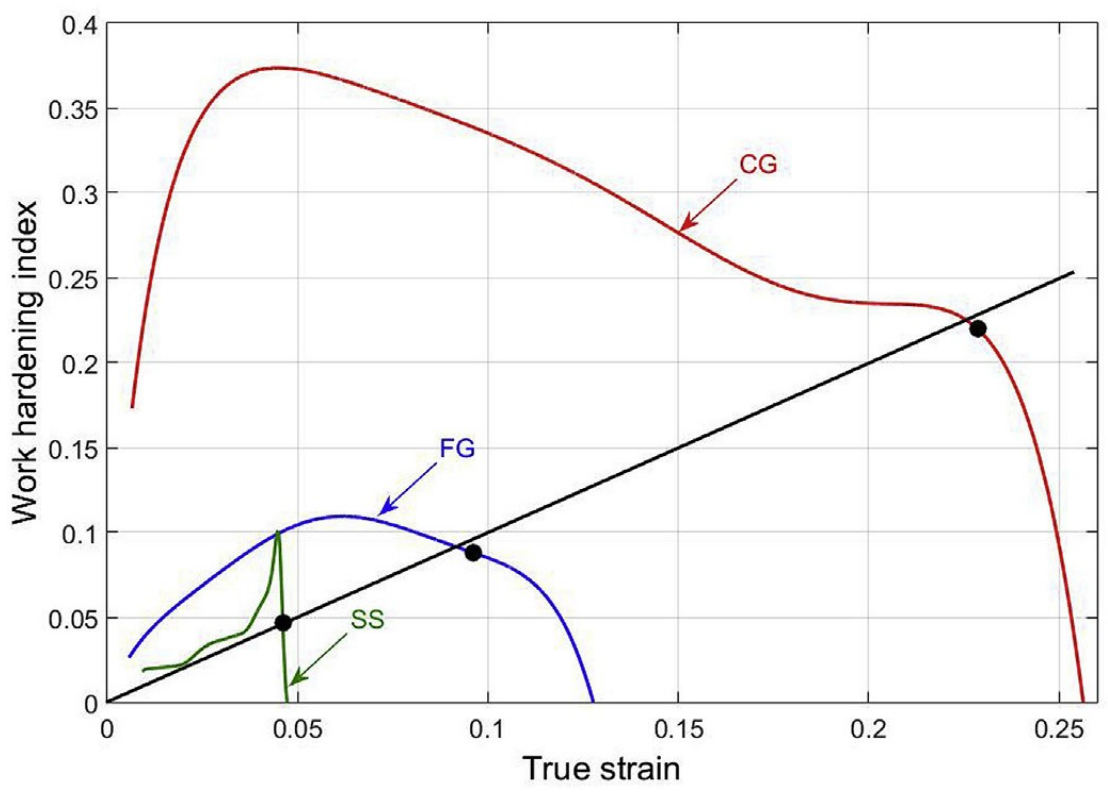


Figure 4. Strain-rate map demonstrating propagation of a deformation band during the yield plateau in a CG sample tested at $5 \times 10^{-3} \mathrm{~s}^{-1}$. The time interval corresponds to the rectangle in the bottom plot which shows the instants on the time-force curve when the images were taken. To provide the maximum contrast, the color scale was determined independently for each frame, based on the instantaneous maximum and minimum strain-rate values. For quantitative comparison, the corresponding maximum values are indicated over each frame. The time instants are given underneath.
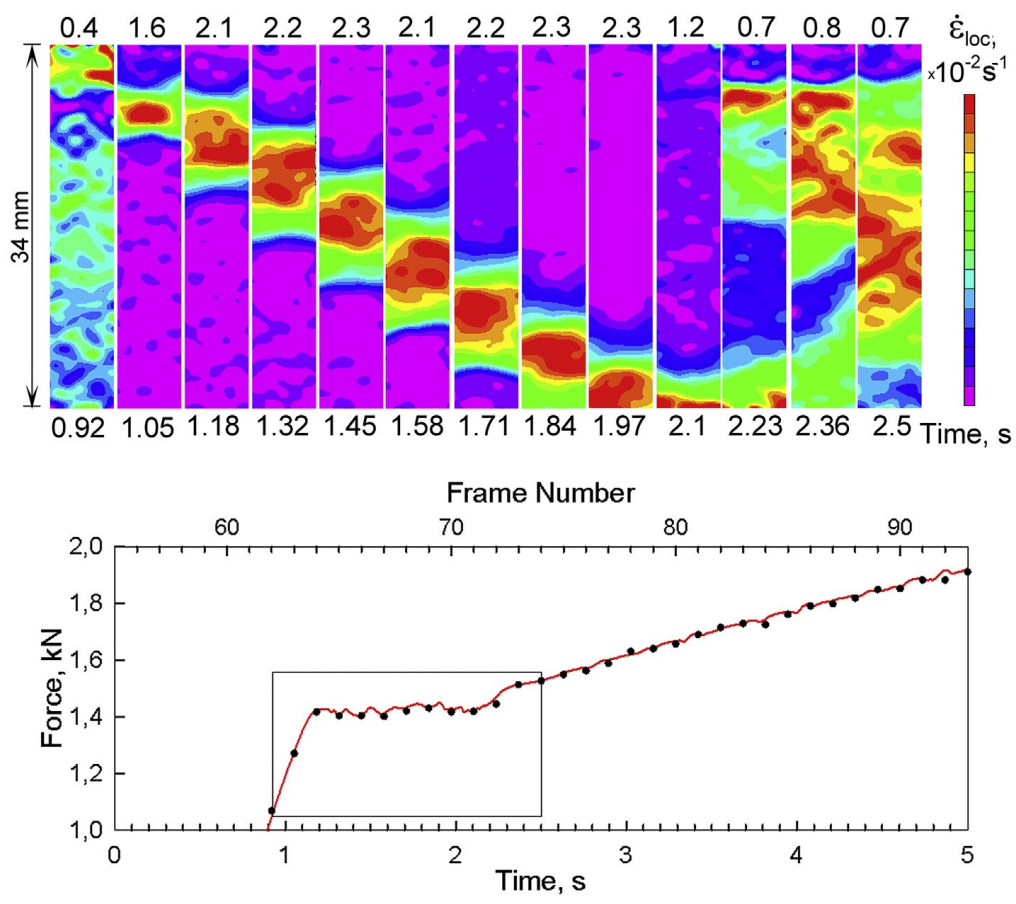

Figure 5. Strain-rate map showing propagation of a type $A$ PLC band in a CG sample on an early deformation stage. $\dot{\varepsilon}_{a}=5 \times 10^{-3} \mathrm{~s}^{-1}$.
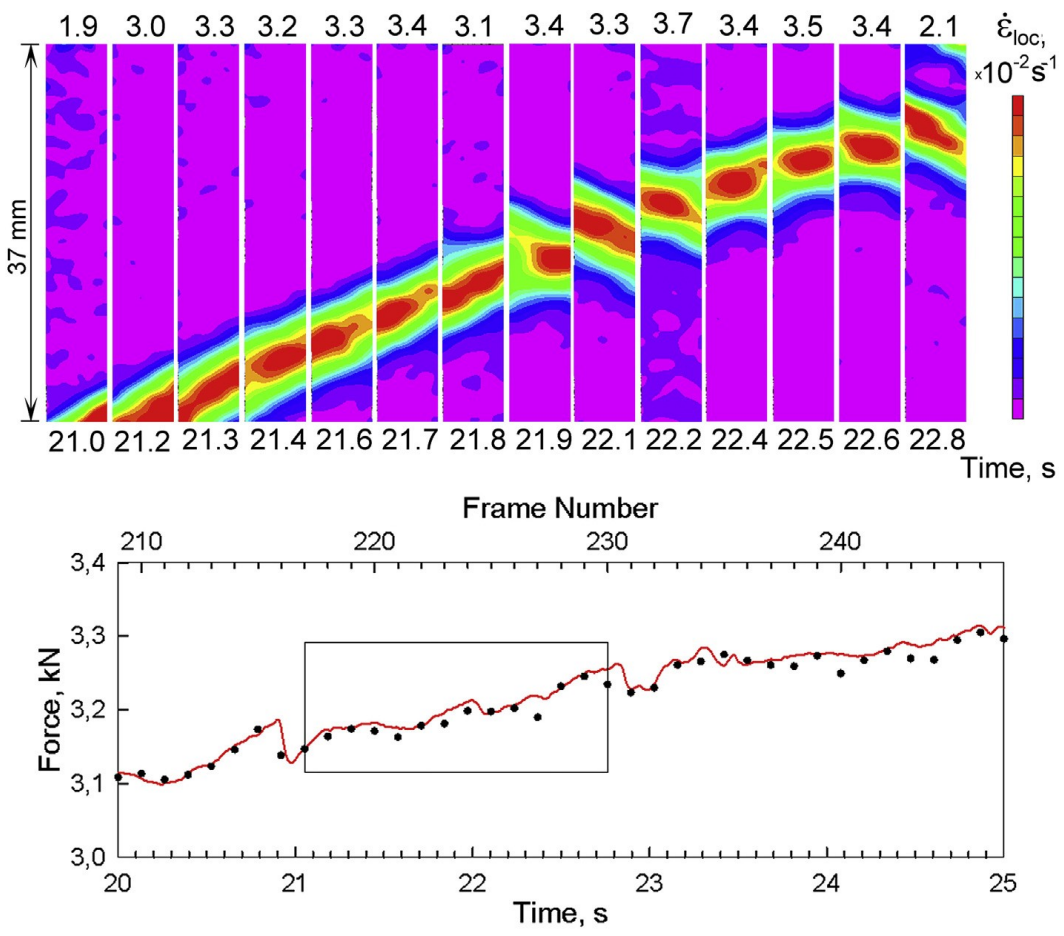
Figure 6. Example of slowing down of the PLC band that acquires a persistent concave shape after significant deformation of the CG sample at $5 \times 10^{-3} \mathrm{~s}^{-1}$.
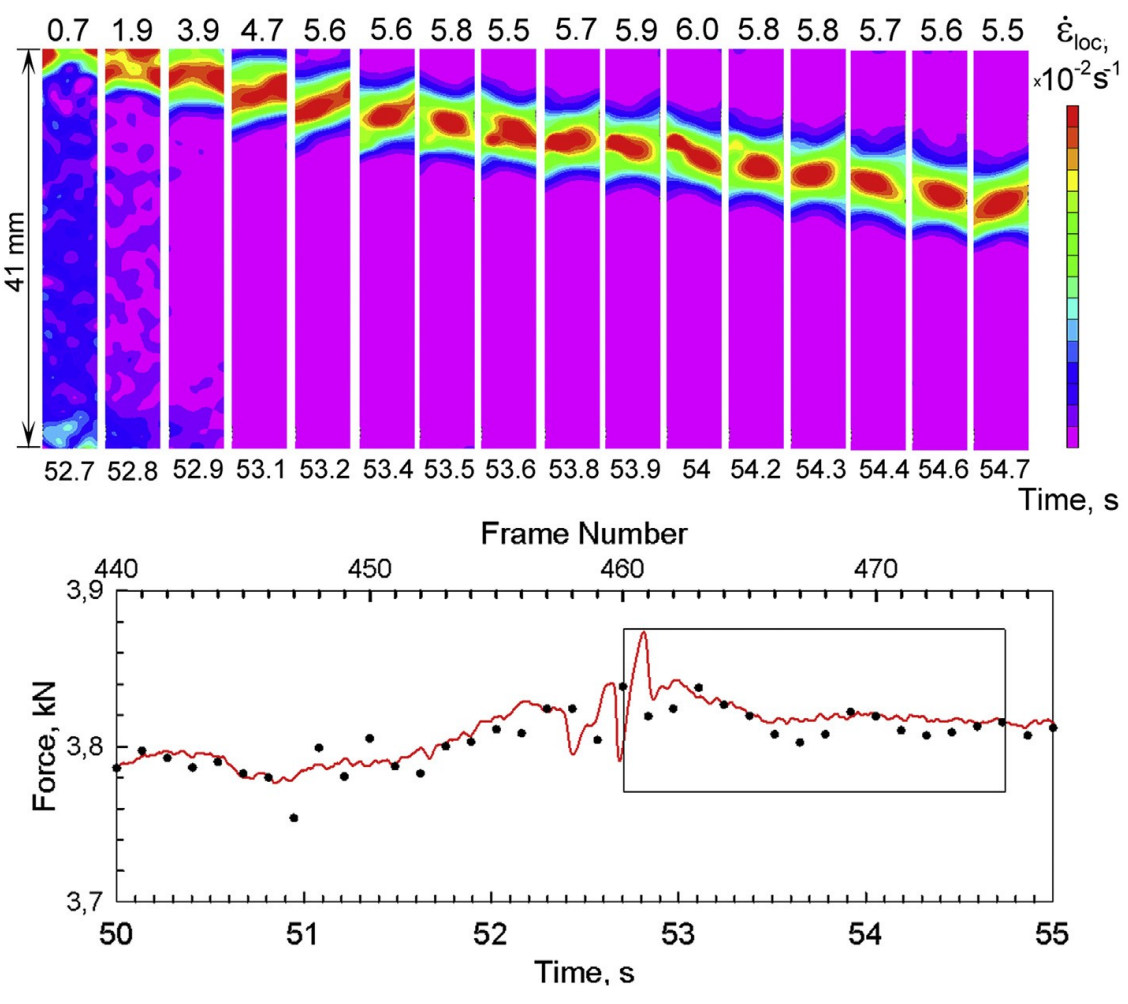

Figure 7. Example of the deformation band localization during necking. The same sample as in Figs. 3-5.
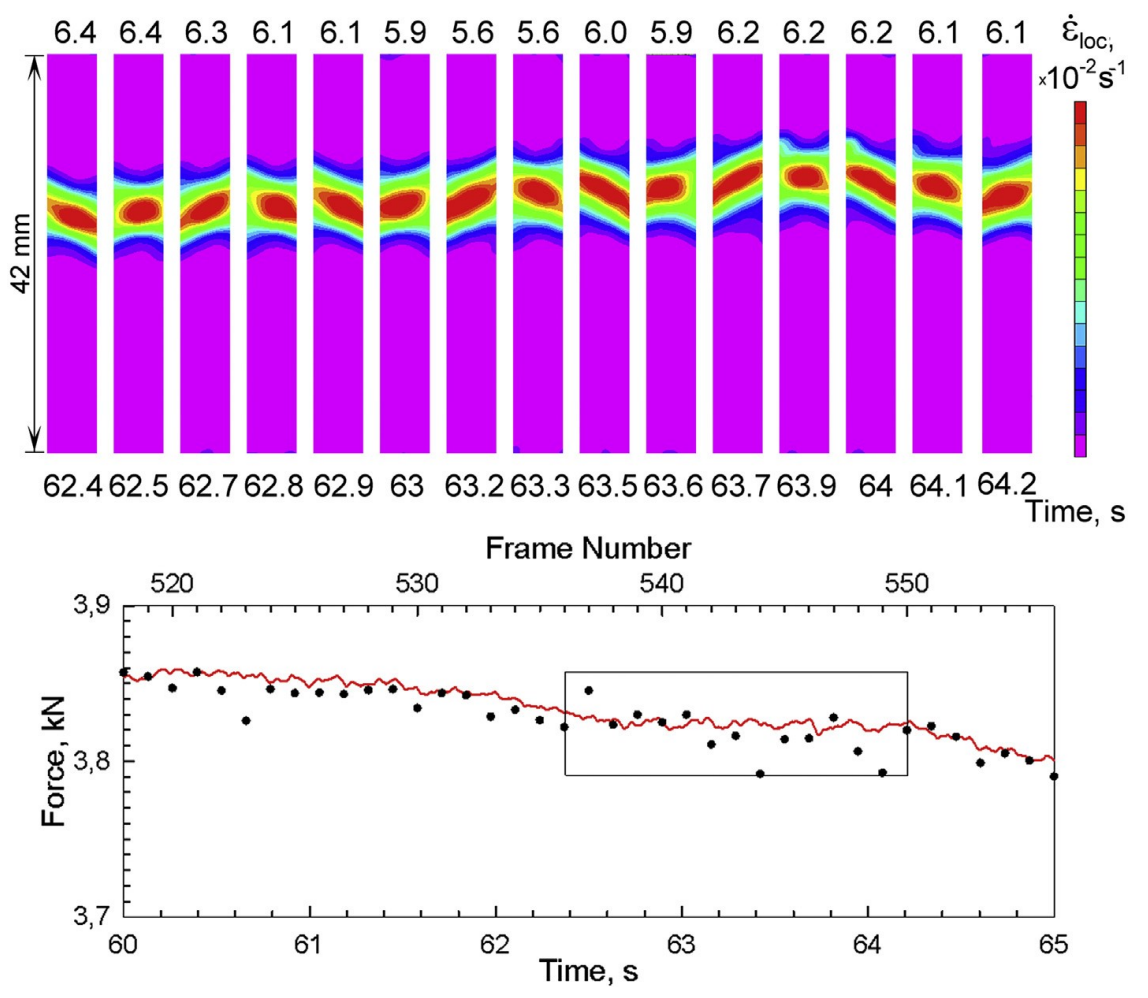
Figure 8. Evolution of the band velocity $V_{b}$ (symbols) and true strain-true stress curves for the specimens of Figs. 4-7 (CG), Figs. 10-11 (FG), and Figs. 12-14 (SS).
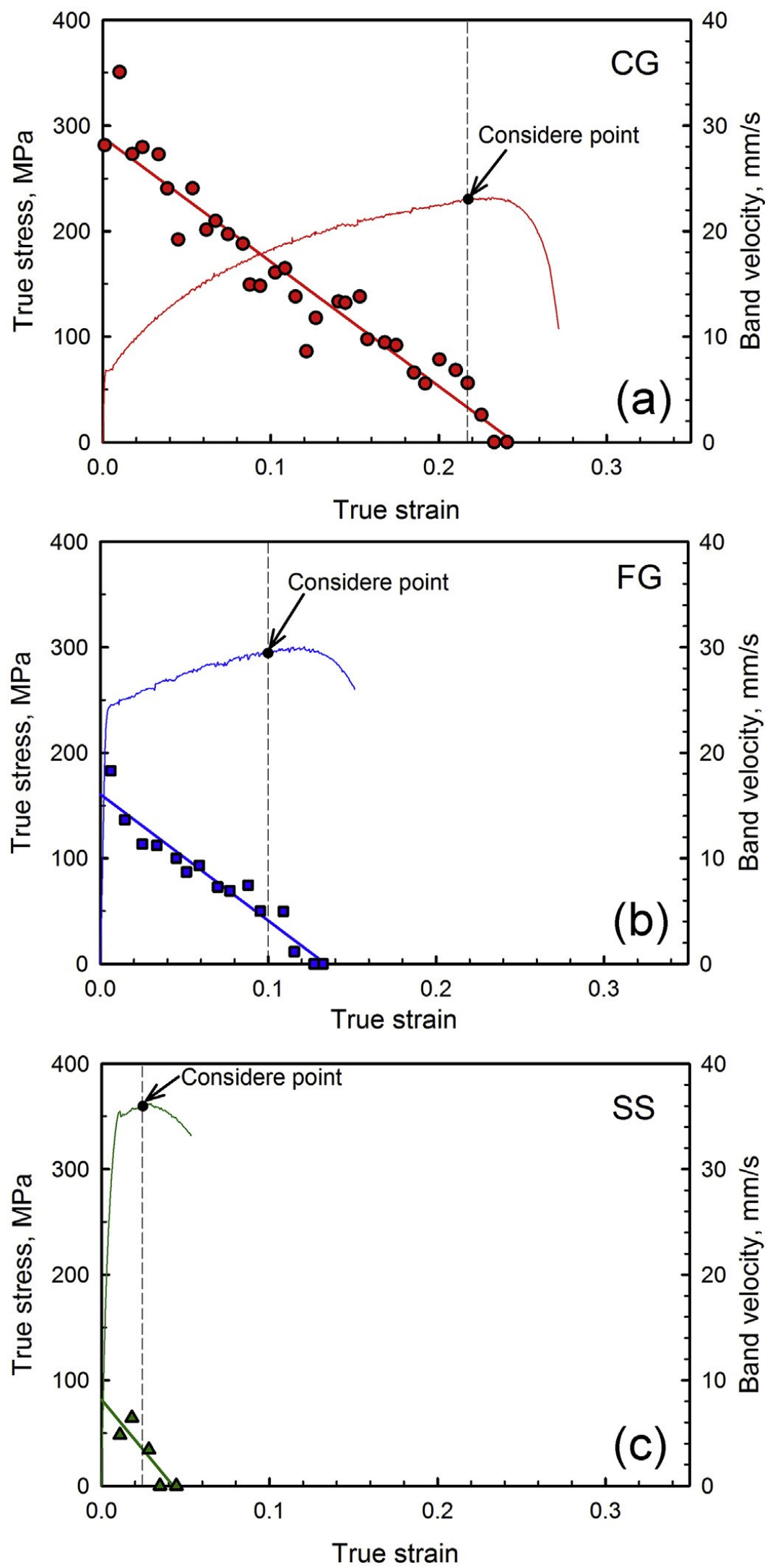
Figure 9. Schematic representation of reversal bending in the necking region.

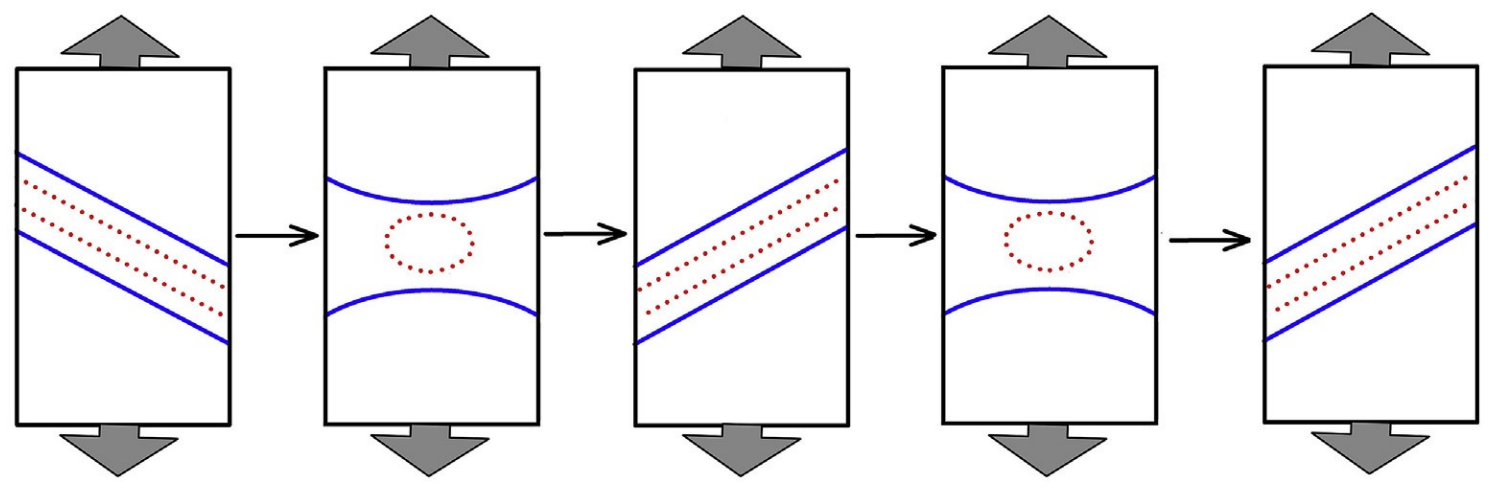

Figure 10. Example of a deformation band propagation in a FG sample tested at $5 \times 10^{-3} \mathrm{~s}^{-1}$.

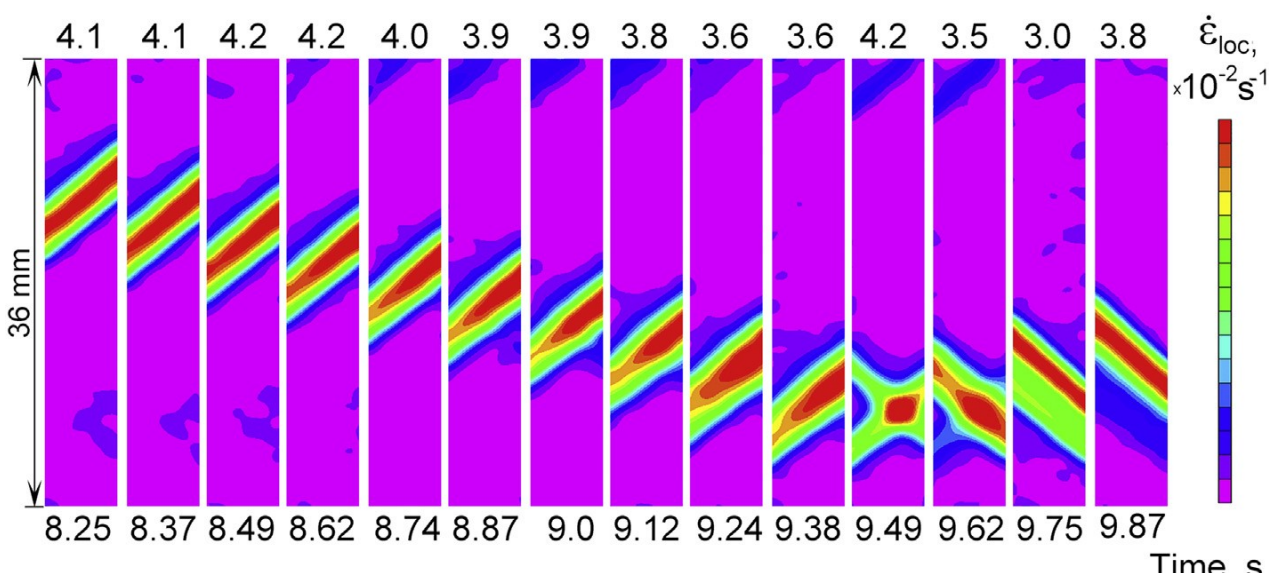

Frame Number

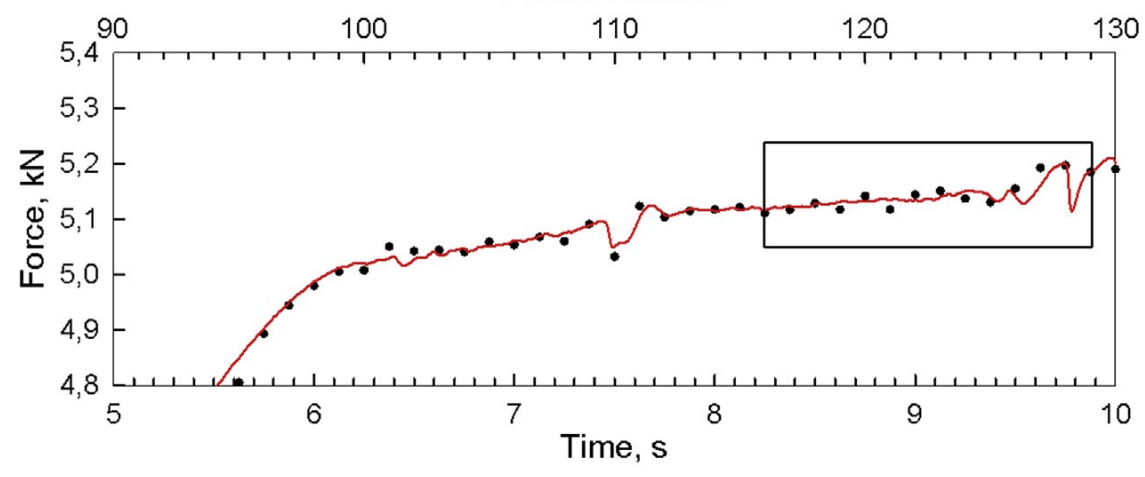


Figure 11. Localized deformation band resulting in neck formation in the FG sample of Figure 12. Formation and propagation of a single deformation band determining the plasticity and fracture of a SS sample tested at $5 \times 10^{-3} \mathrm{~s}^{-1}$.

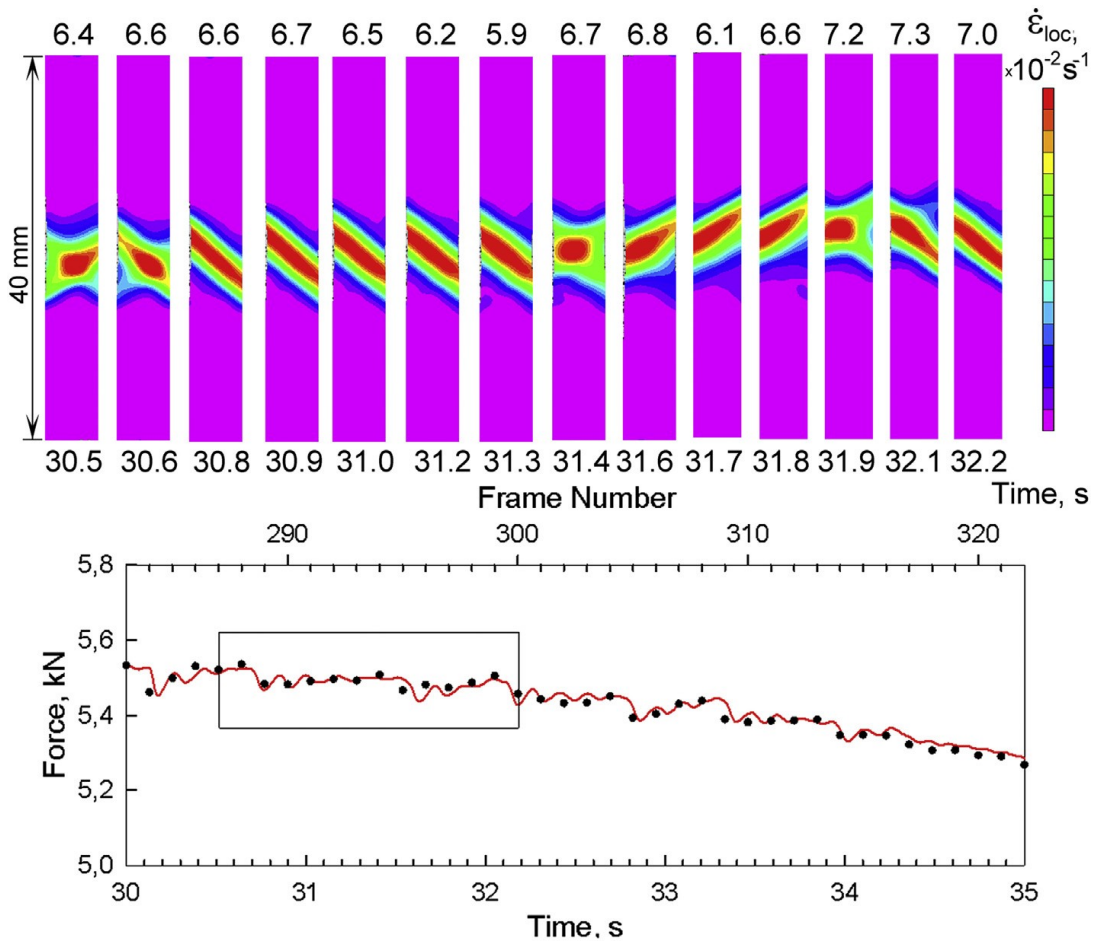

Figure 13. Localized deformation band resulting in neck formation in the SS sample of Fig. 12.

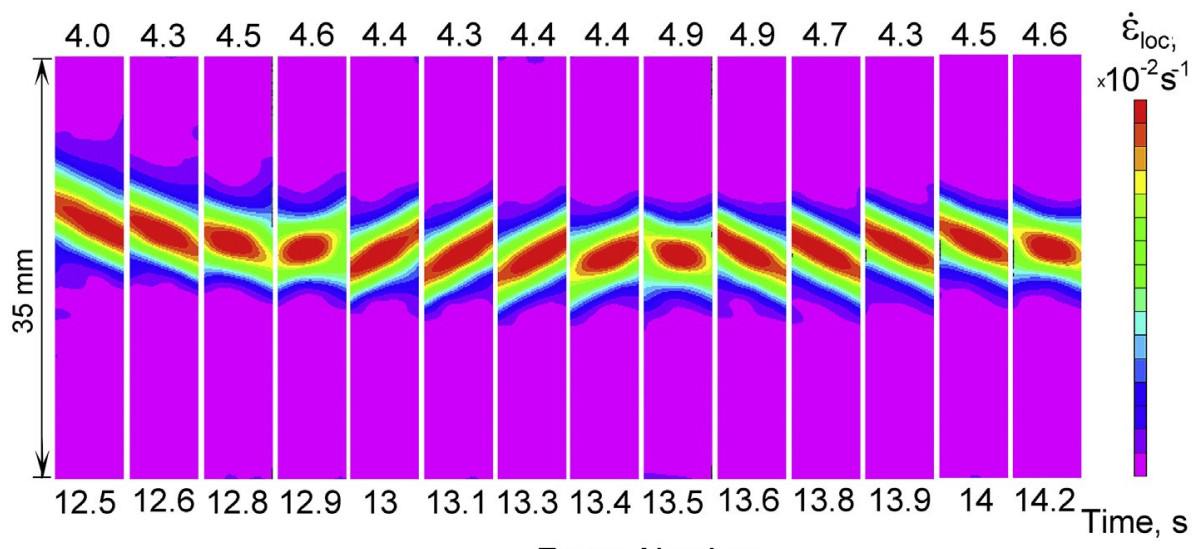

Frame Number

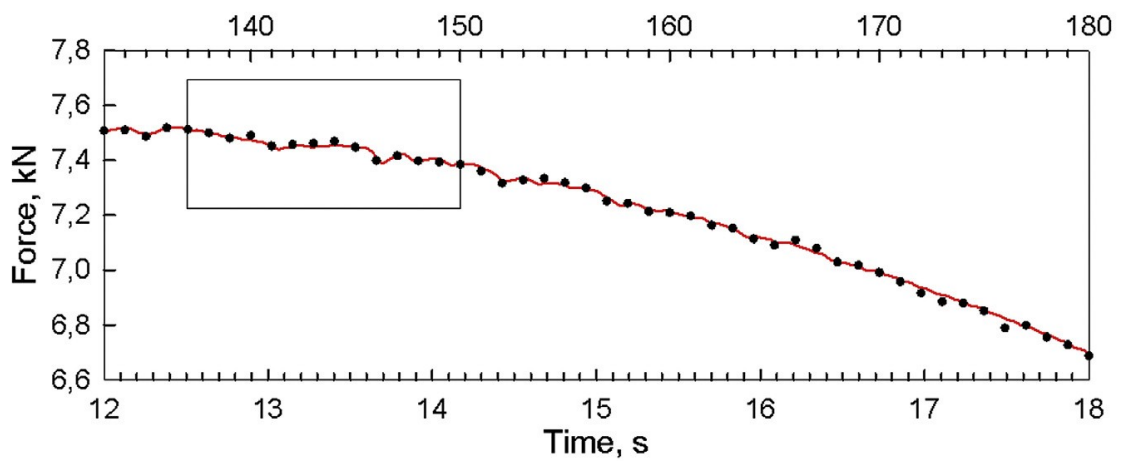


Figure 14. Oscillatory behavior during necking of a SS samples deformed at $1 \times 10^{-3} \mathrm{~s}^{-1}$.

$\begin{array}{lllllllllllllll}6.1 & 11.4 & 32.0 & 30.6 & 9.8 & 5.5 & 4.8 & 5.1 & 5.9 & 10.1 & 31.2 & 32.8 & 11.3 & 5.3 & \dot{\varepsilon}_{\mathrm{loc}}\end{array}$

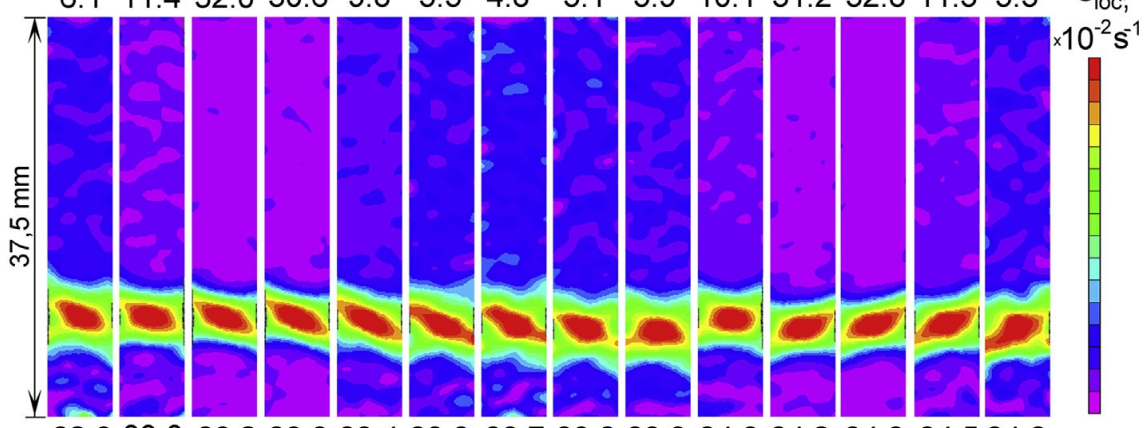

82.9 83.0 83.2 83.3 83.4 83.6 83.7 83.8 83.9 84.0 84.2 84.3 84.5 84.6

Time, $\mathbf{s}$

Frame Number

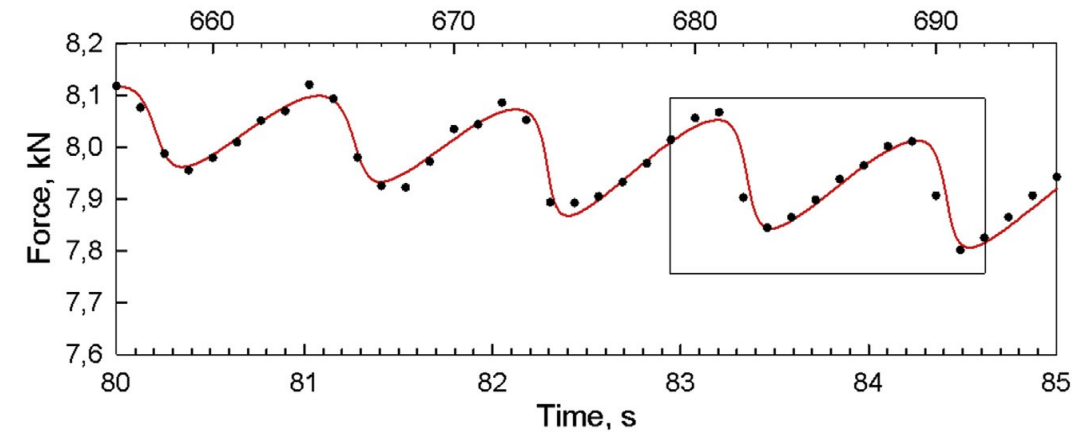

